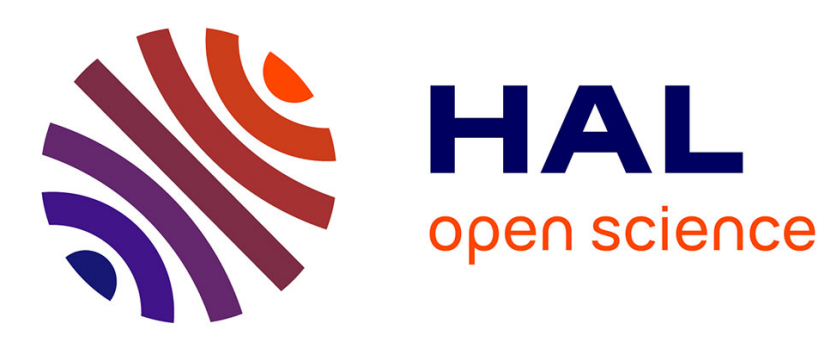

\title{
Sizing of refractory castable gas-burner using thermomechanical simulations
}

Fabien Nazaret, Thierry Cutard, Olivier Barrau

\section{To cite this version:}

Fabien Nazaret, Thierry Cutard, Olivier Barrau. Sizing of refractory castable gas-burner using thermomechanical simulations. Advances in Science and Technology, 2010, 70, p.173-178. hal-01847796

\section{HAL Id: hal-01847796 \\ https://hal.science/hal-01847796}

Submitted on 6 Nov 2018

HAL is a multi-disciplinary open access archive for the deposit and dissemination of scientific research documents, whether they are published or not. The documents may come from teaching and research institutions in France or abroad, or from public or private research centers.
L'archive ouverte pluridisciplinaire HAL, est destinée au dépôt et à la diffusion de documents scientifiques de niveau recherche, publiés ou non, émanant des établissements d'enseignement et de recherche français ou étrangers, des laboratoires publics ou privés. 


\title{
Sizing of refractory castable gas-burner using thermomechanical simulations
}

\author{
F.Nazaret ${ }^{1, a}$, T.Cutard $^{2, b}$ and O.Barrau ${ }^{1, c}$ \\ ${ }^{1}$ AUROCK - 54 rue gustave Eiffel \\ 81000 Albi - FRANCE \\ ${ }^{2}$ Université de Toulouse ; INSA, UPS, Mines Albi, ISAE ; ICA (Institut Clément Ader); Campus \\ Jarlard, F-81013 Albi cedex 09, France \\ anazaret@aurock.fr, ${ }^{b}$ thierry.cutard@mines-albi.fr, ${ }^{c}$ barrau@aurock.fr
}

Keywords: Damage, refractory castables, simulation.

\begin{abstract}
Damage is a crucial characteristic of refractory castables and has to be considered to simulate correctly the behaviour of refractory structures. But, damage modelling by finite element simulations remains difficult. Indeed, the use of a continuum damage model with softening leads to strain localization phenomena. Numerical results depend on the mesh. Several numerical methods allow solving this meshing dependence by introducing an internal length in the material constitutive laws. In this paper, a regularization method has been applied with the damage plasticity model, considering a scalar value for damage. This model enables to take into account permanent strains due to plasticity and damage before and after the peak stress in tension and compression.

Thermomechanical simulations are performed with this model to predict damage in a gas-burner. The damage level is evaluated after a thermal simulation generating high temperature gradients. Interests to take into account damage in the refractory structures are discussed. Sensitivity of results to material properties is studied. This work gives an example of using thermomechanical simulations to improve the design of refractory castable structures and to help in the material choice.
\end{abstract}

\section{Introduction}

Refractory castables present a damage behaviour up to a transition temperature domain located in the $800^{\circ} \mathrm{C}$ to $1100^{\circ} \mathrm{C}$ temperature range. This transition temperature domain depends on the material composition. Beyond this domain, the mechanical behaviour becomes mainly viscoplastic. The present work deals with the damage modelling for temperature values lower than this transition temperature. Considering a such non-linear behaviour is crucial to well predict the high temperature behaviour of complex refractory structures by finite element methods.

Damage behaviour is difficult to reproduce because it generates a strain localization phenomenon and a rigidity loss. During experiments, crack initiation appears after a microcraking developpement in the refractory matrix. Softening behaviour after the peak stress is generated by aggregates cohesion and is characteristic of quasi brittle materials. This mechanism is at the origin of the size effect in quasi-brittle materials [1]. This property allows refractory structures working above the initiation stress level while a stress redistribution phenomenon appears. So, refractory structures are able to support higher load levels compared to structures based on brittle materials. Moreover, damage decreases rigidity and limits stress levels in the structure. That is really important under gradient thermal solicitations.

This paper deals with the study of the behaviour of a gas burner refractory part. This part is submitted to severe solicitations. Damage model is described first. Then, a sensitivity study is performed to evaluate influence of non linear behaviour before the peak stress during simulations of tensile and bending tests. Then, damage modeling is applied to the gas burner part. Results are discussed through damage fields. 


\section{Damage Modeling}

Formulation. Below the transition temperature domain, the mechanical behaviour is divided in two parts. Firstly, the behaviour is linear elastic. When the stress level increases, the behaviour moves to a non-linear one due to diffuse damage processes by microcracking. At higher stress levels, damage localizes and one or several macrocracks initiate. After the peak stress, the behaviour curve exhibits a softening part. The behaviour between compression and tension is asymmetric. The consideration of this phenomenon is taken in account through the yield surface and damage criteria.

To reproduce such as behaviour, a damage plasticity model for quasi brittle materials implemented in the Abaqus ${ }^{\circledR}$ software has been used [3,4]. A strain rate decomposition is assumed for the rate-independent model :

$\dot{\varepsilon}=\dot{\varepsilon}^{e l}+\dot{\varepsilon}^{p l}$

Where $\dot{\varepsilon}$ is the total strain rate, $\dot{\varepsilon}^{e l}$ is the elastic part of the strain rate and $\dot{\varepsilon}^{p l}$ is plastic part of the strain rate. Stress-strain relations are governed by scalar damaged plasticity :

$\boldsymbol{\sigma}=(1-d) \mathbf{D}_{0}^{e l}:\left(\varepsilon-\varepsilon^{p l}\right)=\mathbf{D}^{e l}:\left(\varepsilon-\varepsilon^{p l}\right)$

where $\mathbf{D}_{0}^{e l}$ is the initial (undamaged) elastic stiffness of the material; $\mathbf{D}^{e l}=(1-d) \mathbf{D}_{0}^{e l}$ is the degraded elastic stiffness; and $d$ is the scalar stiffness degradation variable, which can take values in the range from zero (undamaged material) to one (fully damaged material). Damage associated with the failure mechanisms of the concrete (cracking and crushing) therefore results in a decrease of the elastic stiffness. Within the context of the scalar-damage theory, the stiffness degradation is isotropic and characterized by a single degradation variable, $d$. The Cauchy stress is related to the effective stress $\overline{\boldsymbol{\sigma}}$ through the scalar degradation equation:

$\boldsymbol{\sigma}=(1-d) \overline{\boldsymbol{\sigma}}$

Nevertheless, when damage occurs, the effective stress is more representative than the Cauchy stress because it is the effective stress area that is resisting the external loads. It is, therefore, convenient to formulate the plasticity problem in terms of the effective stress. As discussed later, the evolution of the degradation variable is governed by a set of hardening variables, $\widetilde{\varepsilon}^{p l}$, and of the effective stress : $d=d\left(\overline{\boldsymbol{\sigma}}, \widetilde{\varepsilon}^{p l}\right)$.

Damaged states in tension and compression are characterized independently by two hardening variables, $\widetilde{\varepsilon}_{t}{ }^{p l}$ and $\widetilde{\varepsilon}_{c}{ }^{p l}$. They are respectively referred to as equivalent plastic strains in tension and in compression. The evolution of the hardening variables can be expressed as follow :

$\widetilde{\varepsilon}^{p l}=\left[\begin{array}{c}\widetilde{\varepsilon}_{t}^{p l} \\ \widetilde{\varepsilon}_{c}^{p l}\end{array}\right] ; \quad \dot{\widetilde{\varepsilon}}^{p l}=\mathbf{h}\left(\overline{\boldsymbol{\sigma}}, \widetilde{\varepsilon}^{p l}\right) \cdot \dot{\varepsilon}^{p l}$

Microcracking and crushing in the concrete are represented by increasing values of the hardening variables. These variables control the evolution of the yield surface and the degradation of the elastic stiffness. They are directly related to the dissipated fracture energy required to generate micro-cracks too.

The yield function, $F\left(\bar{\sigma}, \widetilde{\varepsilon}^{p l}\right)$, represents a surface in the effective stress space, which determines the state of failure or damage. The yield function enables to reproduce asymmetric behaviour between tension and compression (Fig. 2). Variables $\mathrm{p}$ and q correspond respectively to hydrostatic pressure and to the deviatoric part of the stress tensor.

Plastic flow is governed by a flow potential $G$ according to the flow rule:

$\dot{\varepsilon}^{p l}=\dot{\lambda} \frac{\partial G(\overline{\boldsymbol{\sigma}})}{\partial \overline{\boldsymbol{\sigma}}}$ 
where $\dot{\lambda}$ is the nonnegative plastic multiplier. The plastic potential is defined in the effective stress space. The specific form of the flow potential for the concrete damaged plasticity model is discussed later in this section. The model uses nonassociated plasticity, therefore requiring the solution of nonsymmetric equations.
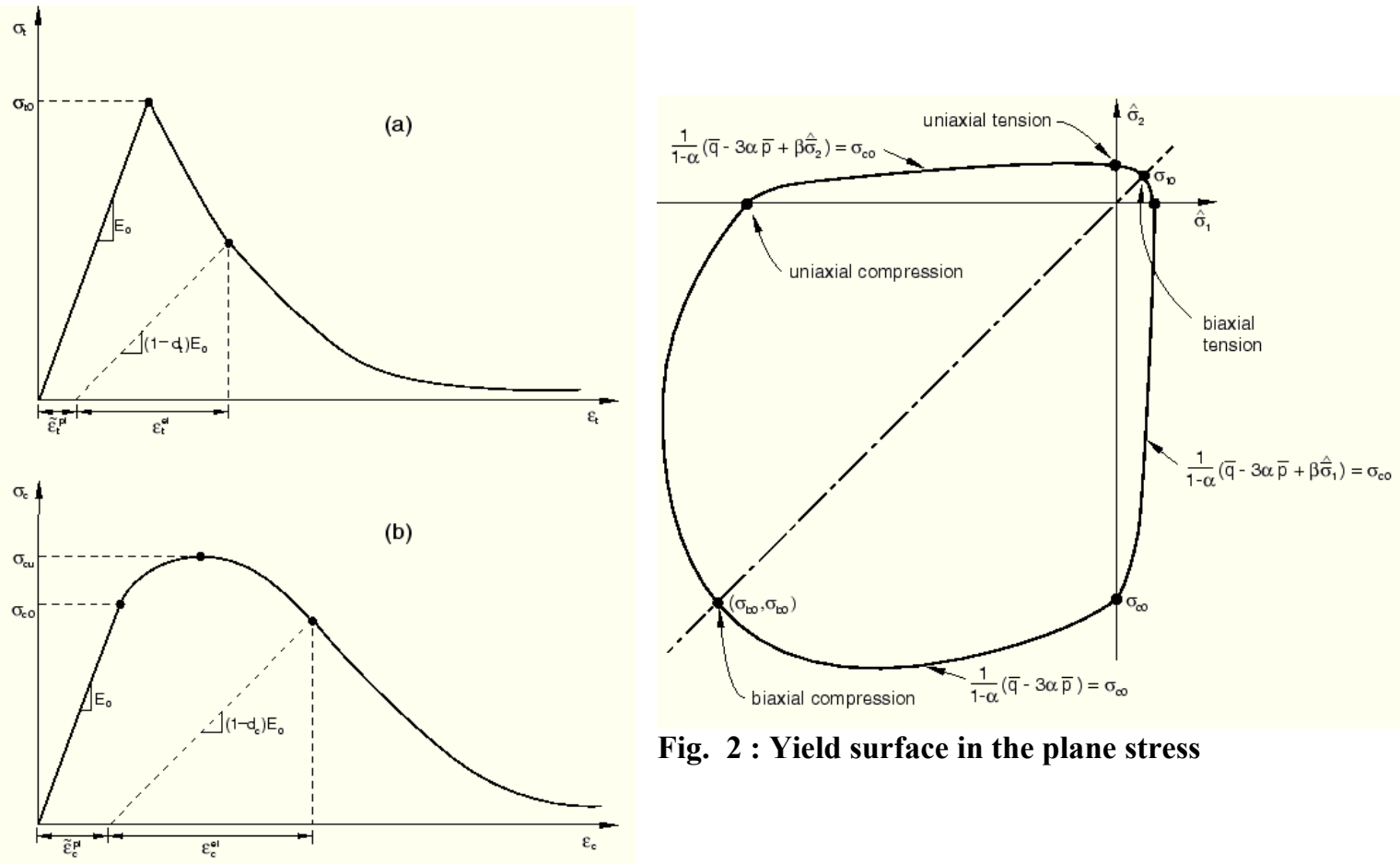

Fig. 2 : Yield surface in the plane stress

Fig. 1 : Response of concrete to uniaxial loading in tension (a) and in compression (b)

Details of uniaxial cyclic conditions and of multiaxial conditions are described in the Abaqus ${ }^{\circledR}$ handbook [3].

The use of a continuum damage model with softening leads to strain localization phenomena. Results depend on the mesh size. A viscoplastic regularization is helpful to obtain the convergence of the model. Several numerical methods allow solving such a meshing dependence problem. They are based on the introduction of an internal length in material constitutive laws. The regularization method with a dependence of the dissipated energy by cracking on the characteristic element length has been chosen [4]. This needs to introduce the post peak behavior as a stress-displacement curve. This curve can correspond to the crack opening measured during a tensile test on a notched sample. The description of the softening behaviour by a stress-displacement curve allows obtaining quite stable simulations even if a severe damage occurs.

Sensitivity study. It's well known that softening behaviour influences highly the macroscopic behaviour during bending tests [5]. This phenomenon is notably very marked for fiber reinforced material [6]. But with some damage models as smeared crack model [7] or Mazars model [8], it's not possible to reproduce non-linear behaviour before the peak stress. Nevertheless, this behaviour domain due to microcraking in the matrix is present for a lot of refractory castables. This domain is often larger at high temperature. To study the influence of this domain on the bending tests, two lists of material parameters determined arbitrarly have been tested. The tensile behaviour established with both sets of material property is represented on the Fig. 3. The softening part is strictly similar for the both data in terms of permanent strains and damage. But for the set numerated 1, none permanent strain is considered before the peak stress. Both curves correspond to classical behaviour in tension of refractory castables. Damage increases quickly after crack initiation.

Four points bending tests have been simulated with these material parameters in 2D modelling imposing a displacement of the upper supports. The behaviour is considered elastic close to contact 
with support to avoid local effects [9]. The load-deflection curve is represented on the Fig. 4. In this figure, stress is calculated using elastic approach. This method enables to compare responses of the both sets of material parameters. For the curve without damage during pre-peak domain, it can be observed that the maximal strength corresponds to the tress level of initiation crack in tension. While the damage is introduced before the peak stress the apparent strength is increased by $80 \%$. At the beginning of the damage apparition at $1.5 \mathrm{MPa}$, the damage repartition is really diffuse and the strain localization occurs later (Fig. 6).
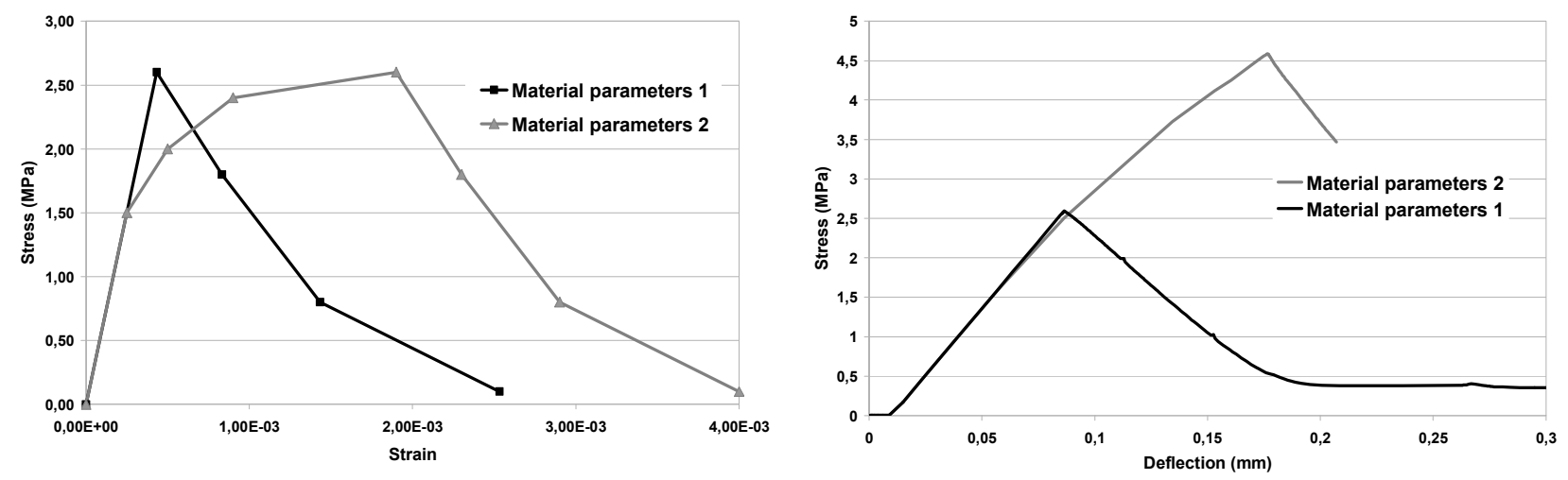

Fig. 3 : Stress-strain curves in tension with material parameters sets

ig. 4 : Stress-deflection curves predicted by simulation of four points bending tests with both material parameters sets

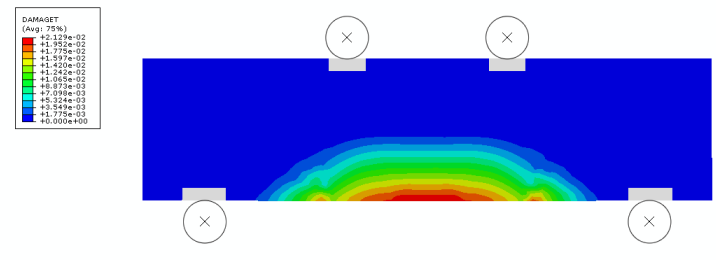

(a)

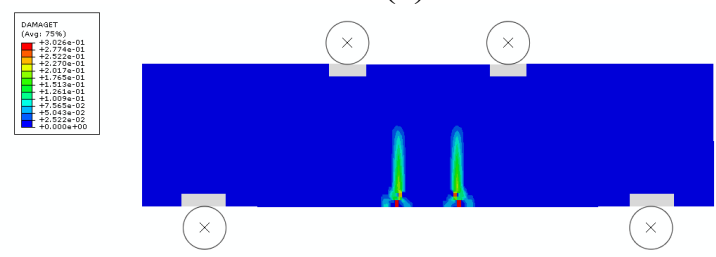

(b)

Fig. 6 : Damage field during bending test with material parameters set 2 (a) at the damage initiation (b) after the maximal strength

The damage plasticity model allows reproducing non-linear behaviour which is often neglected. This domain has a strong influence on the macroscopic behaviour during bending tests. Now, the influence of both sets of material data is going to be used on an industrial refractory part.

\section{Industrial Cases}

Description. This part deals with several simulations performed on a gas burner with a diameter of $400 \mathrm{~mm}$. The structure is made of two refractory castables part. Four injectors are located in the lower refractory block. The assembly is disposed in a steel case (Fig. 7). This structure is submitted to severe thermal gradients induced by convection and heat flux. Convection is imposed by air temperature on all exterior faces. Heat fluxes concern areas close to injectors and in the chimney. A temperature level of $1350^{\circ} \mathrm{C}$ is imposed on the bottom face. The temperature field is calculated from all these thermal boundary conditions by finite element analysis for a steady-state. All parts are tied. Thermal gradients are in the $32^{\circ} \mathrm{C}$ to $1360^{\circ} \mathrm{C}$ temperature range (Fig. 8). 


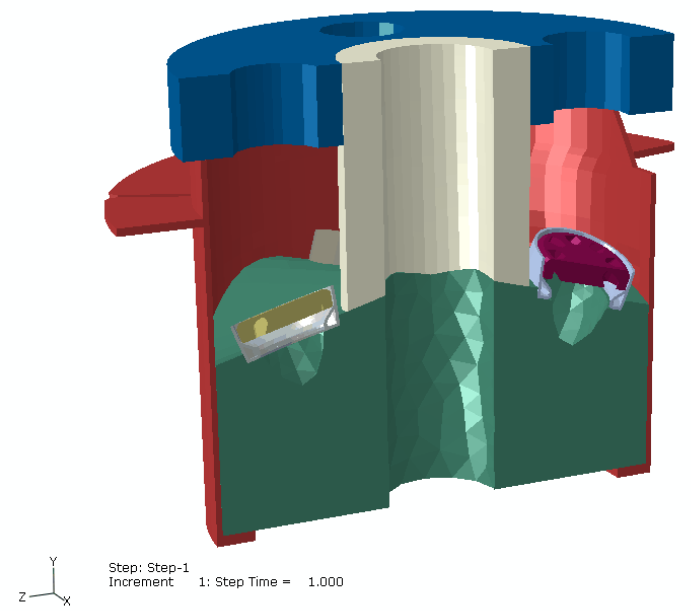

Fig. 7 : Design of the gas burner. The studied refractory part is bottom.

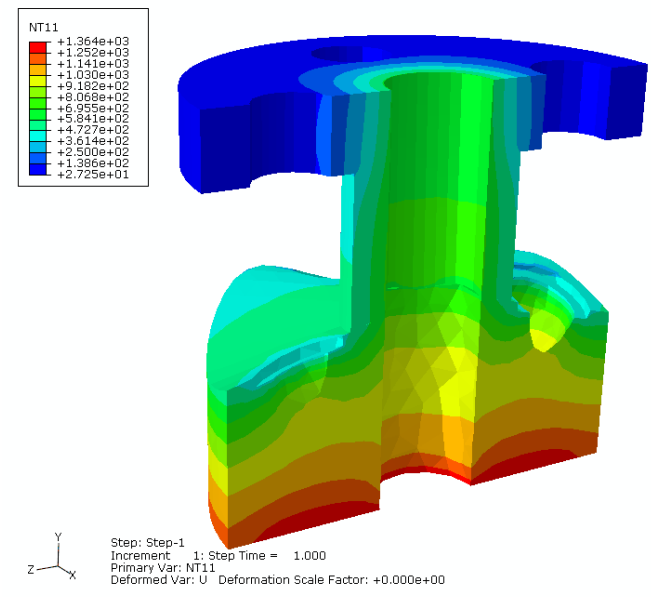

Fig. 8 : Temperature field in the gas burner refractory block

Damage modeling. The thermal field previously calculated has been used to perform simulations using the damage plasticity model. During this thermomechanical simulation, stress level remains low. This is due to crack initiation and propagation phenomena. Damage initiates around holes and propagate up the bottom face and the external faces of the refractory castable part. Without damage before the peak stress, cracks propagate quickly and the damage level reaches the high value of 0.8 for the four main cracks (Fig. 9).

With the second material parameters integrating damage before peak stress, the final value of damage is lower (Fig. 10). Cracks propagate for only two holes. The structure supports larger strains. With these simulations on a complex structure, the important rule of non-linear before the peak stress has been underlined.
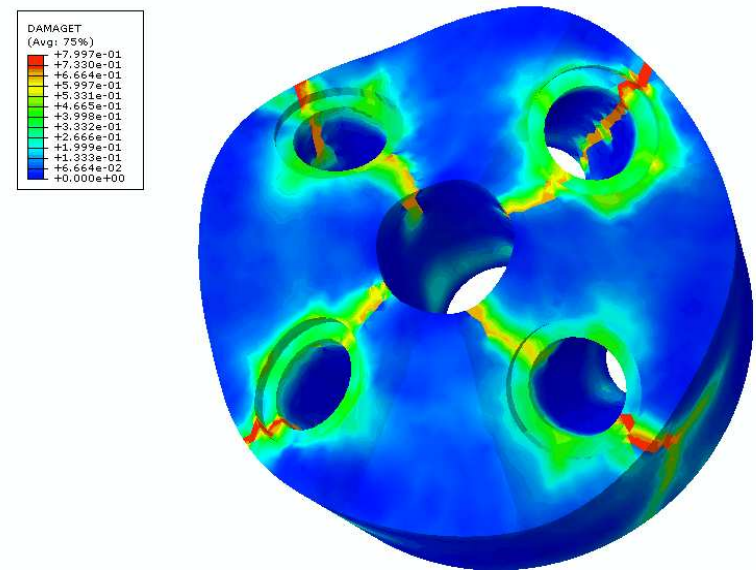

Fig. 9 : Damage field in th gas burner with material parameters set 1

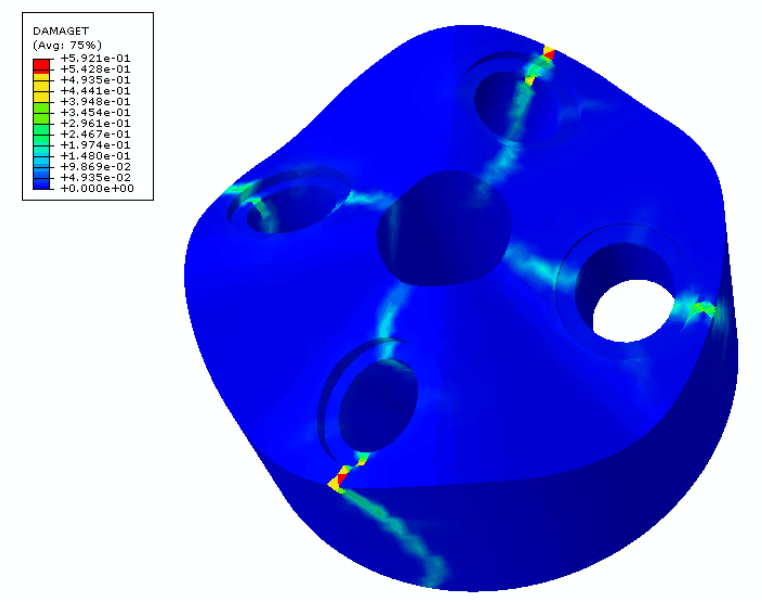

Fig. 10 : Damage field in th gas burner with material parameters set 2

\section{Conclusion}

A damage plasticity model has been used to model damage behaviour in refractory castable. This model implemented in Abaqus ${ }^{\circledR}$ software allows integration of permanent strains before and after the peak stress. This capability gives the possibility to take in account non-linear behaviour classically observed experimentally before the peak stress. This data is often neglected by damage model. Four points bending tests have been simulated with two material parameters sets with and none damage before peak stress. These simulations have shown that the maximal load supported by the sample is increased while the non-linear behaviour before the peak stress is considered. This tendency is reinforced by simulations performed on a complex part in refractory castable submitted 
to several thermal gradients. By considering damage before the peak stress, the crack propagation is less marked and damage level is lower. So, in order to correcly size refractory structure, it's crucial to integrate damage behavior to take in account stress redistribution and to calculate realistic stress levels. The integration of non linear behaviour is also an important issue to not underestimate load supported by a structure.

\section{Acknowledgment}

Authors gratefully acknowledge Loïc LeBars and Optimise society for their technical supports.

\section{References}

[1] Z.P. Bazant, J.Planas, Fracture and size effect in concrete and other quasi-brittle materials, W.F. Chen, 1998.

[2] Abaqus, 2009, Abaqus 6.9, Theory Manual, Abaqus Inc.

[3] J.Lubliner, J.Oliver, S.Oller, E.Onate, A plastic-damage model for concrete, International Journal of Material Science, Vol. 25, No 3, 1989, 299-326.

[4] A.Hillerborg, "Application of the fictitious crack model to different types of materials", International Journal of Fracture, Vol.51, 1991, 95-102.

[5] F.Nazaret, Caractérisation et modélisation d'un béton réfractaire renforcé de fibres métalliques, Thesis, Ecole des Mines de Paris, 2005.

[6] J. F. Olesen, Fictitious crack propagation in fiber-reinforced concrete beams, Journal of Engineering Mechanics, 127, 3, (2001), pp. 272-280.

[7] J. G. Rots et J. Blaauwendraad, Crack models for concrete : discrete or smeared? Fixed, multidirectional or rotating?, Heron, 34, 1, (1989), pp. 1-59

[8] J. Mazars, Application de la mécanique de l'endommagement au comportement non linéaire et à la rupture du béton de structure, Paris 6, (1984)

[9] F.Nazaret, H.Marzagui, T.Cutard, "Influence of the mechanical behaviour specificities of damaged refractory castables on the Young's modulus determination", Journal of the European Ceramic Society, Vol.26, 2006, 1429-1438. 